\title{
Level of Satisfaction in Patients attending Government Health Facilities of AIIMS, New Delhi, Outreach Outpatient Department, Badsa, Jhajjar, Haryana, India
}

\author{
${ }^{1}$ Arvind Kumar, ${ }^{2}$ Birakta Debbarma, ${ }^{3}$ Anup Singh, ${ }^{4}$ Kuldeep Kumar, ${ }^{5}$ Anupam K Singh, ${ }^{6}$ Prayas Sethi, ${ }^{7}$ Arvind Kumar
}

${ }^{8}$ Lalit Kumar, ${ }^{9}$ Shakti K Gupta

\begin{abstract}
Customer satisfaction is an individual feeling of pleasure or disappointment resulting from comparing a product/service's perceived performance or outcome in relation to his or her expectations. Outpatient department (OPD) in any hospital is considered to be a shop window of the hospitals. Our study aims to extract patient's satisfaction through structured questionnaire covering all dimensions like interpersonal manner of health service providers, accessibility, physical environment, and quality of medical care. It was a cross-sectional questionnaire-based study conducted at the All India Institute of Medical Sciences (AIIMS), New Delhi, outreach OPD, over 2 years from November 2014 to February 2016 and included 402 participants. The satisfactions divided into low, medium, and high were found in $17.91,67.66$, and $14.42 \%$ respectively. Medium satisfaction was similar in almost all qualification and occupation groups, which could be a subject of perception. Income-wise, upper class had highest level of satisfaction. Among the five divisions of questionnaire, accessibility to health care facility raised some concern from patient point of view, probably this being an outreach OPD. Other four factors like availability of medical resources, interpersonal manner, behavior of health care personnel, and physical environment of health care facility drew similar attention from the participants. The AIIMS outreach OPD can be taken as one of the steps in improving the outreach facility.
\end{abstract}

Keywords: Outreach outpatient department, Patient satisfaction, Questionnaire.

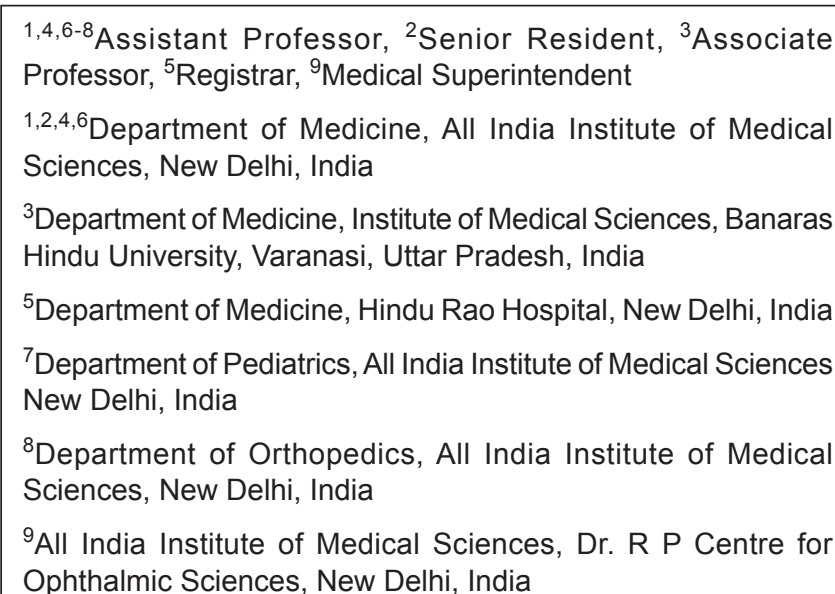

Corresponding Author: Shakti K Gupta, Medical Superintendent All India Institute of Medical Sciences, Dr. R P Centre for Ophthalmic Sciences, New Delhi, India, Phone: +919818837782 e-mail: Shakti810505@gmail.com
How to cite this article: Kumar A, Debbarma B, Singh A, Kumar K, Singh AK, Sethi P, Kumar A, Kumar L, Gupta SK. Level of Satisfaction in Patients attending Government Health Facilities of AlIMS, New Delhi, Outreach Outpatient Department, Badsa, Jhajjar, Haryana, India. Int J Res Foundation Hosp Healthc Adm 2018;6(1):22-30.

\section{Source of support: Nil}

Conflict of interest: None

\section{INTRODUCTION}

Customer satisfaction is an individual feeling of pleasure or disappointment resulting from comparing a product or service's perceived performance and outcome in relation to his or her expectations. The role of government in ensuring that the country's health care system provides optimal services for its population has been greatly emphasized upon. ${ }^{1}$ All health care providers and programs in our country have an overwhelming emphasis on quantitative aspect of services delivered, which means that, in a quest to chase runaway targets, we often neglect the concept of quality of care, which is also a right of patients. ${ }^{2}$ Outpatient department in any hospital is considered to be a shop window of the hospitals. Nowadays, patients are looking for hassle-free and quick services. This demand is only possible with optimum utility of the resources through multitasking in a single-window system of the OPD. ${ }^{3}$ Monitoring patient satisfaction has some advantages over other clinical outcome indicators. Patient satisfaction indicators remain stable over time as opposed to clinical indicators, which will be changed with technology and pace of medical progress. ${ }^{4}$ Patient satisfaction is determined by the cultural setting of the people served. Medical care that fulfills the social and emotional needs of the patients is highly accepted. It is determined by the interplay of two factors, i.e., patient's or client's expectations and the real services provided. If the performance falls short of expectations, the customer is dissatisfied and if the performance matches the expectations, he is satisfied. In case the performance exceeds expectations, the client is highly satisfied or delighted.

Patient's satisfaction means patient's attitudes and perceptions toward health care services. Being 
intangible and subjective phenomenon, it is not easy to define. Patient satisfaction is "The degree to which the individual regards the health care as useful, effective and beneficial." ${ }^{\prime 5}$ Patient satisfaction has been defined as an evaluation and reaction based on the fulfillment of expectations. 5,6 "It is the reflection of experiences of the customers for their expectations and needs." ${ }^{7}$ People's use of health services is influenced by a range of psychological, social, cultural, economic, and political forces. ${ }^{8}$ Health care includes several services; therefore, there are several factors of patient's satisfaction from doctors, nurses, treatment, general environment, and management. An attempt to evaluate the level of patient's satisfaction is related to different parameters of quality health care at the health facilities. This provides the existing medical system certain parameters that need improvement in the quality of the service provided. ${ }^{9}$ Almost all the research on user perceptions includes questions about the personality, expertise, behavior, and interpersonal skills of the doctors. Patients have high expectations from the doctors in terms of showing care for the patient, extending consultation and support. The study of doctor-patient relationship is critical in customizing the doctors' attitude according to the user requirements. ${ }^{10,11}$

\section{Asian Data}

The patient satisfaction data from Asian studies from Sharma et $\mathrm{al}^{12}{ }^{12}$ Prasanna et $\mathrm{al}^{8}{ }^{8}$ and Verma and Sharma ${ }^{13}$ have varied from around 50 to $80 \%$. Factors like registration procedure, doctor behavior, waiting times, transportation, and doctor skill have been independently explored in these studies. ${ }^{14-16}$ However, due to lack of a structured questionnaire covering all domains of patient satisfaction and lack of internal consistency and reproducibility, these surveys give only partial information. Our study hence, aims to fulfill this lacuna by covering all patient satisfaction dimensions like interpersonal manner of health service providers, accessibility, physical environment, and availability and quality of medical care. ${ }^{17}$

Therefore, a study was conducted to investigate the level of satisfaction in patients attending government health facilities at the AIIMS, New Delhi outreach OPD Jhajjar, Badsa, Haryana, around $46 \mathrm{~km}$ away from the main campus.

\section{MATERIALS AND METHODS}

\section{Study Design}

It was a cross-sectional questionnaire-based study conducted at the outreach clinic, Jhajjar. The target population of this study included all patients who utilized health services at the OPD clinic of AIIMS Jhajjar. Parents or guardians were the respondents of patients of age less than 14 years. Jhajjar outreach clinic was selected as the study site. The health facility catered to the population of the Jhajjar district and the nearby villages with the total of 956,907 population (source 2011 census). ${ }^{18}$ This is an outreach OPD facility center having various departments (lab facility, radiodiagnosis, medicine, surgery, orthopedics, obstetrics and gynecology, pediatrics, ear, nose and throat facility, and ophthalmology) run by AIIMS, New Delhi. The study was carried out over nearly two years from November 2014 to February 2016 with sampling done mainly in winter season (2014-2015 and 2015-2016) between December and January. Similar weather was chosen to maintain coherence in satisfaction related to environmental conditions.

\section{Sample Size Determination}

Sample size was calculated using the formula, sample size $(n)=z^{2} p(1-p) / d^{2}$ assuming a beta error $=0.2$, corresponding power of $80 \%$, and $Z=Z$-score when $95 \%$ confidence interval for estimating client satisfaction $Z$ was equal to 2.58 , When alpha error $=5 \%$, corresponding to $99 \%$ confidence interval, where $\mathrm{p}=$ prevalence of patient satisfaction, $\mathrm{d}=$ allowable error $6.5 \%$. As we presumed maximum variability, hence, $\mathrm{p}=0.5$; sample size thus yielded was 393. Adding a figure of $10 \%$ for incomplete interviews, the total number came out to be 430 which was rounded off and 450 patients were interviewed. Selecting only the completed, fully legible, and completed pro formas, 402 of them were finally analyzed.

\section{Sampling Technique}

Systematic random sampling was applied to draw the patients in order to get information about the aspects of health services. The sampling data collection was done once a week on different days to cover heterogeneity in patient population across days. Patients were selected within a $\mathrm{k}$ interval. The k interval is calculated by using this formula: $\mathrm{k}=\mathrm{a} / \mathrm{n} \times \mathrm{d}$, where $\mathrm{k}=$ sampling interval, $\mathrm{a}=$ actual number of patients who consumed services at the OPD clinic per day $(\mathrm{a}=225), \mathrm{d}=8$ (equivalent to 8 weeks, thus spread over 2 months in one season), $\mathrm{n}=$ required number of patients who consumed services at the OPD clinic $(n=450)$.

Thus, by this formula $\mathrm{k}=4$.

\section{Research Instrument}

The research instrument was a structured questionnaire (Annexure 1) which was adapted and modified from wellvalidated questionnaire for primary health care satisfaction in Thailand. ${ }^{19}$ The questionnaire was translated into Hindi language which is used locally in the study area. 
Annexure 1: Questionnaire used in the study (modified version of Net et al ${ }^{19}$ questionnaire of satisfaction) which was scored on a 1 to 5 scale developed by Ware, Snyder, and Wright, $1976=$ Excellent Satisfaction (81-100\%), 4 = Good Satisfaction (61-80\%), $3=$ Satisfied (41-60\%), 2 = Dissatisfied (21-40\%), 1 = Poor satisfaction (<20\%); and some was also stratified on Likert's system as "strongly agree," "agree," "neither agree nor disagree," "disagree," and "strongly disagree."

\begin{tabular}{|c|c|c|c|c|c|c|}
\hline \multirow{2}{*}{\multicolumn{2}{|c|}{$\begin{array}{l}\text { No. Statements } \\
\text { Interpersonal manner of health service providers }\end{array}$}} & \multicolumn{5}{|c|}{ Satisfaction level } \\
\hline & & 1 & 2 & 3 & 4 & 5 \\
\hline 1 & Physicians examine and treat me in a very friendly and courteous manner & & & & & \\
\hline 2 & Physicians and their staff who treat me should give me more respect about my wishes & & & & & \\
\hline 3 & $\begin{array}{l}\text { When I am receiving medical care, physicians and their staff should pay more attention } \\
\text { to my privacy }\end{array}$ & & & & & \\
\hline 4 & I feel free to complain about my health problem when I am with my physicians & & & & & \\
\hline \multicolumn{7}{|c|}{ Accessibility } \\
\hline 5 & $\begin{array}{l}\text { Staffs at the reception ease me to obtain all information I need about health services } \\
\text { here }\end{array}$ & & & & & \\
\hline 6 & There are enough seats at the waiting area & & & & & \\
\hline 7 & I do not have to wait too long for getting medical care at this OPD & & & & & \\
\hline 8 & I find it hard to get an appointment for medical care right away at this OPD & & & & & \\
\hline 9 & Places where I get medical care are very conveniently located & & & & & \\
\hline \multicolumn{7}{|c|}{ Physical environment } \\
\hline 10 & The location of services is clean and has enough space to use & & & & & \\
\hline 11 & I feel the atmosphere of this OPD is good & & & & & \\
\hline 12 & $\begin{array}{l}\text { There are clear signs and directions to indicate where to go in the service area of this } \\
\text { OPD }\end{array}$ & & & & & \\
\hline 13 & Facilities and equipment at the OPD are tidy & & & & & \\
\hline \multicolumn{7}{|c|}{ Availability of medical resources } \\
\hline 14 & Physicians and their health staffs are available whenever I need during my visit & & & & & \\
\hline 15 & $\begin{array}{l}\text { I think my physician's office has adequate medical instruments and equipment needed } \\
\text { to provide complete medical care }\end{array}$ & & & & & \\
\hline \multicolumn{7}{|c|}{ Quality of care } \\
\hline 16 & Physicians are careful to check everything when examining and treating me & & & & & \\
\hline 17 & $\begin{array}{l}\text { Medical instruments and equipment that physicians use when examining and treating } \\
\text { me are very clean }\end{array}$ & & & & & \\
\hline 18 & The ability of physicians, pharmacists who give me medical care services is perfect & & & & & \\
\hline 19 & $\begin{array}{l}\text { My physicians and their staff are very competent and have experiences with my medical } \\
\text { problem }\end{array}$ & & & & & \\
\hline 20 & Medications I receive are good and well-packed & & & & & \\
\hline 21 & Registration procedure & & & & & \\
\hline 22 & Time given by doctor & & & & & \\
\hline 23 & Overall patient global satisfaction & & & & & \\
\hline
\end{tabular}

A pretest of 23 questionnaires was conducted in the OPD clinic prior to the actual data collection for its reliability and feasibility. In the pretest, the values of "Cronbach's alpha" coefficient satisfaction parts were determined. We proceeded with the study only if "Cronbach alpha" value of greater than 0.7 was found and the questionnaire was easily understandable for our patients and data collectors in our resource-limited setting. Socioeconomic status was classified according to "BG Prasad classification" ${ }^{20}$ system based on precipitate income updated according to May 2014 (Annexure 2).

\section{RESULTS}

In our study, data of 402 patients were analyzed. The mean age of our study group was 38.19 years [standard deviation (SD) 16.18\%], the majority of them being females
Annexure 2: BG Prasad classification system of socioeconomic status used in the study

\begin{tabular}{ll}
\hline $\begin{array}{l}\text { Socioeconomic } \\
\text { classification }\end{array}$ & Value in INR (last reference May 2014) \\
\hline I (Upper) & 1. 5571 INR per capita and above \\
II (Upper middle) & 2. 2786-5570 INR \\
III (Middle) & 3. 1670-2786 INR \\
IV (Lower middle) & 4. 836-1670 INR \\
V (Lower) & 5. Upto 836 INR
\end{tabular}

[315 (53.5\%)] and education wise, number and percentage of illiterate, primary school (up to 5th standard), high school (up to 10th standard), senior secondary (plus two), graduate, and postgraduate were $68(16.9 \%)$, $27(6.7 \%), 11$ (2.7\%), 123 (30.6\%), 100 (24.9\%), 62 (15.4\%), and $11(2.7 \%)$ respectively (Table 1$)$. Occupation wise, the number and percentage of housewives and unemployed 
Table 1: Demographic and socioeconomic profile of population under study

\begin{tabular}{ll}
\hline Profile of the participants & Number of patients (n) \\
\hline Demography & 402 \\
Age, mean (SD) & $38.19(16.18)$ \\
Sex $=$ M (\%) & $187(46.5)$ \\
Education & \\
- Illiterate & $68(16.9)$ \\
- Up to 5th standard & $27(6.7)$ \\
- 6 to 7th standard & $11(2.7)$ \\
- 8 to 10th standard & $123(30.6)$ \\
- Senior secondary & $100(24.9)$ \\
- Graduate & $62(15.4)$ \\
- Postgraduate & $11(2.7)$ \\
Occupation & \\
- Housewife/unemployed & $194(48.3)$ \\
- Farmer & $54(13.4)$ \\
- Student & $26(6.5)$ \\
- Government job & $40(10.0)$ \\
- Private job & $80(19.9)$ \\
- Business & $8(2.0)$ \\
Income & \\
- 5571 INR per capita and above & $299(74.4)$ \\
- 2786-5570 INR & $58(14.4)$ \\
- 1670-2786 INR & $15(3.7)$ \\
- 836-1670 INR & $12(3.0)$ \\
- Up to 836 INR & $18(4.5)$ \\
\hline
\end{tabular}

males together constituted around 194 out of total 402 which constituted the majority $48.3 \%$. Farmers, students, government employees, private firm employees, and businesspersons were $54(13.4 \%), 26(6.5 \%), 40(10 \%), 80$ $(9.9 \%)$, and $8(2.0 \%)$ respectively. Socioeconomic status on BG Prasad classification consisted of 299 out of 402 over 5,571 /month INR, 58 patients ( $14.4 \%$ ) had income less than 5,571, but more than 2,786 INR, 15 (3.7\%), 12 (30\%), and $18(45 \%)$ patients had income that ranged from 1,670 to 2,786, 836 to 1,670, and up to 836 INR respectively.

The questionnaire (Annexure 1) grossly dealt with issues under five major subheadings that were: Accessibility to health care facility, availability of medical resources, interpersonal manner and behavior of health care personal, physical environment of health care facility, and quality of health care. The overall satisfaction was classified into three by dividing the average of all the scores (Table 2) into lower third (low satisfaction), middle third (medium satisfaction), and upper third percentile (high satisfaction). As shown in Graph 1, the global satisfaction of the patients (patients') toward health services at the outreach OPD clinic of AIIMS, New Delhi, was found to be low, medium, and high satisfaction as in $17.91,67.66$ and $14.42 \%$ respectively.

Table 2: Characteristics of patients in the study divided into low, medium, and high level of satisfaction groups

\begin{tabular}{|c|c|c|c|c|}
\hline & Low & Medium & High & $p$-value \\
\hline $\mathrm{n}$ & 72 & 272 & 58 & \\
\hline Age [mean (SD)] & $40.40(17.74)$ & $38.15(16.26)$ & $35.62(13.43)$ & 0.246 \\
\hline Sex $=M(\%)$ & $38(52.8)$ & $115(42.3)$ & $34(58.6)$ & 0.039 \\
\hline Education (\%) & & & & $<0.001$ \\
\hline - Illiterate & $18(25.0)$ & $49(18.0)$ & $1(1.7)$ & \\
\hline - Up to $5^{\text {th }}$ standard & $6(8.3)$ & $17(6.2)$ & $4(6.9)$ & \\
\hline - 6 to $7^{\text {th }}$ standard & $5(6.9)$ & $6(2.2)$ & $0(0.0)$ & \\
\hline - 8 to $10^{\text {th }}$ standard & $16(22.2)$ & $102(37.5)$ & $5(8.6)$ & \\
\hline - Senior secondary & $16(22.2)$ & $60(22.1)$ & $24(41.4)$ & \\
\hline - Graduate & $8(11.1)$ & $36(13.2)$ & $18(31.0)$ & \\
\hline - Postgraduate & $3(4.2)$ & $2(0.7)$ & $6(10.3)$ & \\
\hline Occupation (\%) & & & & 0.026 \\
\hline - Housewife/unemployed & $35(48.6)$ & $140(51.5)$ & $19(32.8)$ & \\
\hline - Farmer & $17(23.6)$ & $27(9.9)$ & $10(17.2)$ & \\
\hline - Student & $6(8.3)$ & $17(6.2)$ & $3(5.2)$ & \\
\hline - Govt. job & $5(6.9)$ & $28(10.3)$ & $7(12.1)$ & \\
\hline - Private job & $9(12.5)$ & 54 (19.9) & $17(29.3)$ & \\
\hline - Business & $0(0.0)$ & $6(2.2)$ & $2(3.4)$ & \\
\hline Income (\%) & & & & $<0.001$ \\
\hline - 5571 INR per capita and above (upper) & $59(81.9)$ & $213(78.3)$ & $27(46.6)$ & \\
\hline • 2786-5570 INR (upper middle) & $5(6.9)$ & $43(15.8)$ & $10(17.2)$ & \\
\hline • 1670-2786 INR (middle) & $0(0.0)$ & $8(2.9)$ & $7(12.1)$ & \\
\hline • 836-1670 INR (lower middle) & $0(0.0)$ & $4(1.5)$ & $8(13.8)$ & \\
\hline - Up to 836 INR (lower) & $8(11.1)$ & $4(1.5)$ & $6(10.3)$ & \\
\hline Accessibility [mean (SD)] & $3.66(0.57)$ & $4.34(0.39)$ & $4.91(0.10)$ & $<0.001$ \\
\hline Availability [mean (SD)] & $3.56(0.73)$ & $4.45(0.48)$ & $5.00(0.00)$ & $<0.001$ \\
\hline Interpersonal [mean (SD)] & $4.05(0.63)$ & $4.68(0.33)$ & $5.00(0.00)$ & $<0.001$ \\
\hline Physical environment [mean (SD)] & $3.52(0.50)$ & $4.51(0.46)$ & $5.00(0.00)$ & $<0.001$ \\
\hline Quality [mean (SD)] & $3.85(0.57)$ & $4.62(0.34)$ & $5.00(0.02)$ & $<0.001$ \\
\hline
\end{tabular}




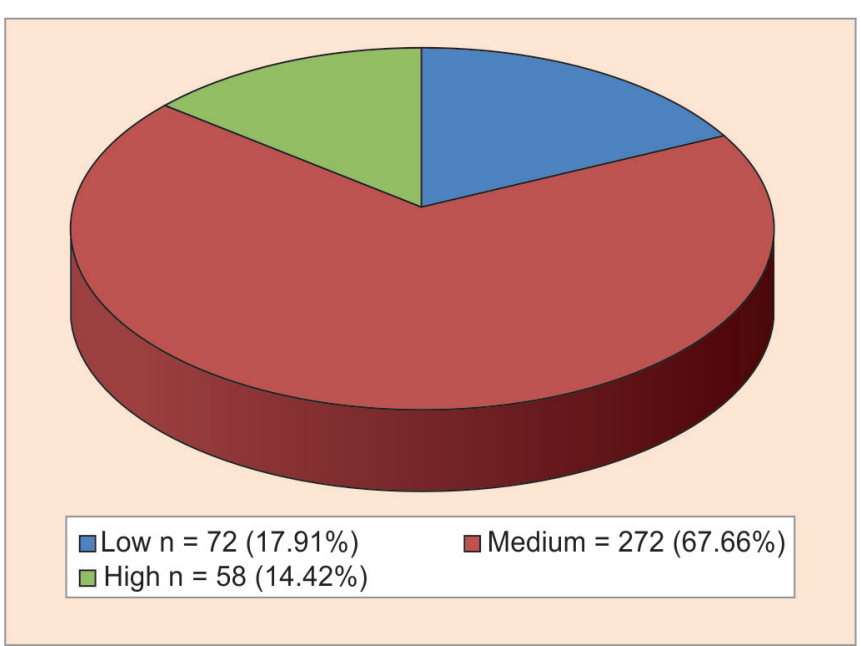

Graph 1: Overall satisfaction of the patients attending the government facility at AIIMS outreach OPD, Badsa, Jhajjar, Haryana

\section{Distribution of Scores}

Visualization at distribution of scores (Graph 2, Violin plot) suggests that score for most questions has bimodal peak of 4 (satisfied) and 5 (very satisfied) respectively in all five domains. In interpersonal and quality domains, most items had greater than $50 \%$ of very satisfied (5) responses, while in the accessibility domain, greater than $10 \%$ cases had a less than 4 (neutral or dissatisfied) response.

\section{Comparison of Scores across Domains}

We did an analysis of variance (ANOVA) of scores across domains. The ANOVA was significant (F-value $=21$, $\mathrm{p}<0.0001)$. Tukey's post hoc analysis suggests that while

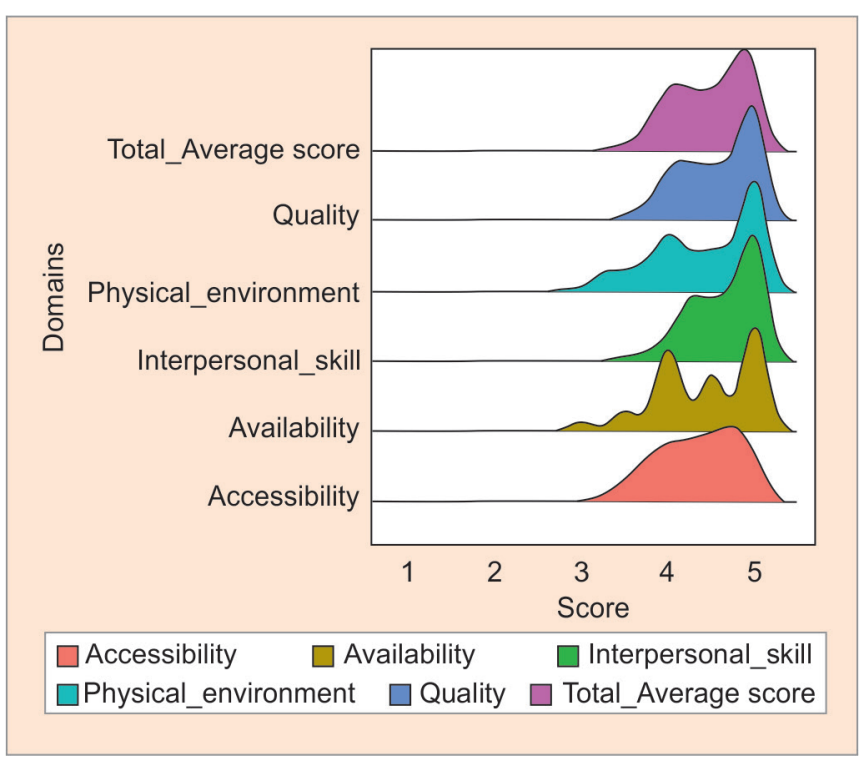

Graph 2: Distribution of various scores and their predominance among various parameters the scores having highest peak in almost all the groups of around 4 to 5 , where 5 was the maximum score given

quality and interpersonal skills domains have significant higher scores than other domains like availability, accessibility, and physical environment, though there is no statistically significant difference between quality and interpersonal Skills (Annexure 3).

\section{Confirmatory Factor Analysis}

A confirmatory factor analysis was conducted on the 23 items with orthogonal rotation which assumes that items are correlated. The Kaiser-Meyer-Olkin (KMO)

Annexure 3: Tukey's post hoc analysis of difference between domain scores post one-way ANOVA

\begin{tabular}{|c|c|c|c|}
\hline \multicolumn{4}{|l|}{ \$Domains } \\
\hline & diff & Iwr & upr \\
\hline Availability-Accessibility & 0.07014925 & -0.038178796 & 0.17847730 \\
\hline Interpersonal-Accessibility & 0.31579602 & 0.207467971 & 0.42412407 \\
\hline Physical_Environment-Accessibility & 0.10435323 & -0.003974815 & 0.21268128 \\
\hline Quality-Accessibility & 0.23899254 & 0.130664488 & 0.34732059 \\
\hline Interpersonal-Availability & 0.24564677 & 0.137318717 & 0.35397482 \\
\hline Physical_Environment-Availability & 0.03420398 & -0.074124069 & 0.14253203 \\
\hline Quality-Availability & 0.16884328 & 0.060515234 & 0.27717133 \\
\hline Physical_Environment-Interpersonal & -0.21144279 & -0.319770835 & -0.10311474 \\
\hline Quality-Interpersonal & -0.07680348 & -0.185131532 & 0.03152457 \\
\hline Quality-Physical_Environment & $\begin{array}{l}0.13463930 \\
\text { p adj }\end{array}$ & 0.026311254 & 0.24296735 \\
\hline Availability-Accessibility & 0.3926757 & & \\
\hline Interpersonal-Accessibility & 0.0000000 & & \\
\hline Physical_Environment-Accessibility & 0.0653889 & & \\
\hline Quality-Āccessibility & 0.0000000 & & \\
\hline Interpersonal-Availability & 0.0000000 & & \\
\hline Physical_Environment-Availability & 0.9106676 & & \\
\hline Quality-Availability & 0.0002115 & & \\
\hline Physical_Environment-Interpersonal & 0.0000011 & & \\
\hline Quality-Interpersonal & 0.2986533 & & \\
\hline Quality_Physical_Environment & 0.0063212 & & \\
\hline
\end{tabular}


Annexure 4: Cronbach alpha representing internal consistency of domains of score

\begin{tabular}{lll}
\hline Domains & Test_retest_reliability & Cronbach_alpha \\
\hline Interpersonal & 0.74 & 0.79 \\
Accessibility & 0.60 & 0.68 \\
Physical_Environment & 0.78 & 0.81 \\
Availability & 0.58 & 0.66 \\
Quality & 0.82 & 0.91 \\
\hline
\end{tabular}

(Annexure 4) measure verified the sampling adequacy for the analysis $\mathrm{KMO}=0.93$, and all $\mathrm{KMO}$ values for individual items were $>0.77$, which is well above the acceptable limit of 0.5. Bartlett's test of sphericity, $\chi^{2}(253)=19.334$, $\mathrm{p}<0.001$, indicated that correlations between items were sufficiently large. An initial analysis was run to obtain eigenvalues for each component in the data. While five components had eigenvalues over Kaiser's criterion of 1 and in combination explained $64 \%$ of the variance, component 1 (made up of majority of questions of quality of care domain, 16 to 23 ) accounted for $23 \%$ of variance, component 2 (made of majority of questions in accessibility domain, 6 to 9) accounted for $20 \%$ of variance. Component 3 accounted for $9 \%$ of variance (had 2 out of 4 questions from environment domains). Components 4 and 5 together accounted for $11 \%$ of variance and had component not specific to predefined domains in questionnaire and varying amounts of cross-talk.

The scree plot (Annexure 5) was slightly ambiguous and showed inflexions that would justify retaining anywhere between two and three components. Given the large sample size, and the convergence of the scree plot and meeting Kaiser's criterion on five components, five components were retained in the final analysis. However, it is clear from the analysis that component 1 (quality of care) and component 2 (accessibility) capture maximum amount of variance.

Annexure 5: Scree plot showing eigenvalue variation with number of factors in principal component analysis

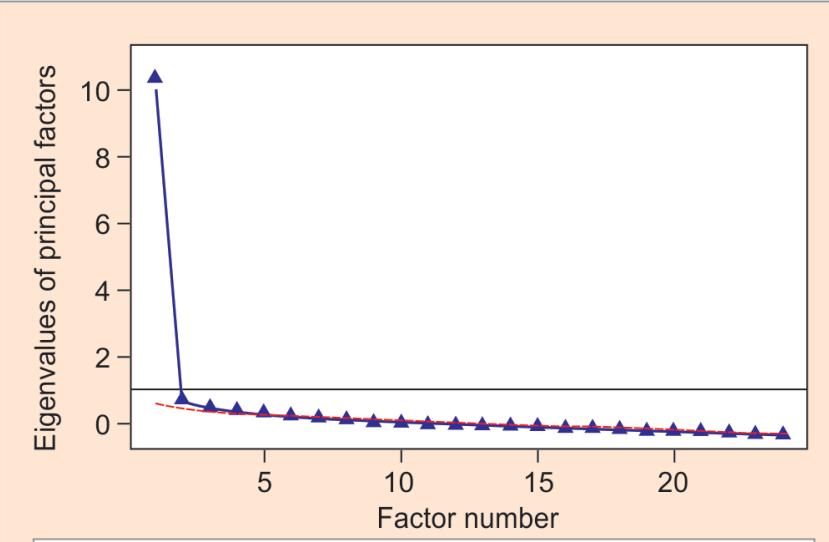

* FA actual data

....... FA simulated data ----. FA resampled data

\section{Internal Consistency}

The internal consistency of subscales (domains) varied from 0.91 (quality of care) to 0.66 (availability). The accessibility and availability domains had lower than recommended value of 0.7 , indicating that questions in these domains need to be worded more appropriately for more internal consistency. Test-retest reliability (testing the same questionnaire on the same patients after a duration of thirty minutes) also followed a similar trend like Cronbach alpha.

\section{Multivariate Analysis}

We carried out a multiple linear regression with average score as dependent variable and other predictor domain scores as independent variables. The model had significant goodness of fit. (R square $=0.98$ ). The coefficient of regression estimates shows that one-point improvement in quality will lead to 0.29-point improvement in mean score while controlling for other variables. Corresponding values for other domains are 0.22 for physical environment, 0.20 for accessibility, 0.08 for availability, and 0.12 for interpersonal skills; other variables are nonsignificant. It implies that quality and physical environment play a major role in affecting average score in our study. The forest plot of regression coefficients is shown in Annexure 6.

\section{Predictor Factors}

On correlation matrix of age with domain scores, we see that higher age is negatively correlated with all domains, while higher income and better occupation status are associated with better scores on all domains (Annexure 7).

While age has been seen to have a negative correlation in other studies as well, income and occupation are negatively correlated in other studies, but positively correlated in our study.

The results show that medium satisfaction was more in almost all qualification group and the same also holds true with different occupation groups with $\mathrm{p}$-value being significant for both $<0.001$ and $<0.026$ respectively. Income wise, in upper class, most of them has medium satisfaction, followed by low satisfaction, and least had high satisfaction, while upper middle and middle had mostly medium satisfaction, followed by high satisfaction and least had low level of satisfaction. Lower middle had highest satisfaction, followed by medium-level satisfaction while lower class, most of them had low level of satisfaction, followed by high level of satisfaction, and then least had medium level of satisfaction. Among the five major subheadings of the complete questionnaire, most of them $(n=272)$ had medium level of satisfaction 
Annexure 6: Forest plot showing coefficients of effect of domains on mean score

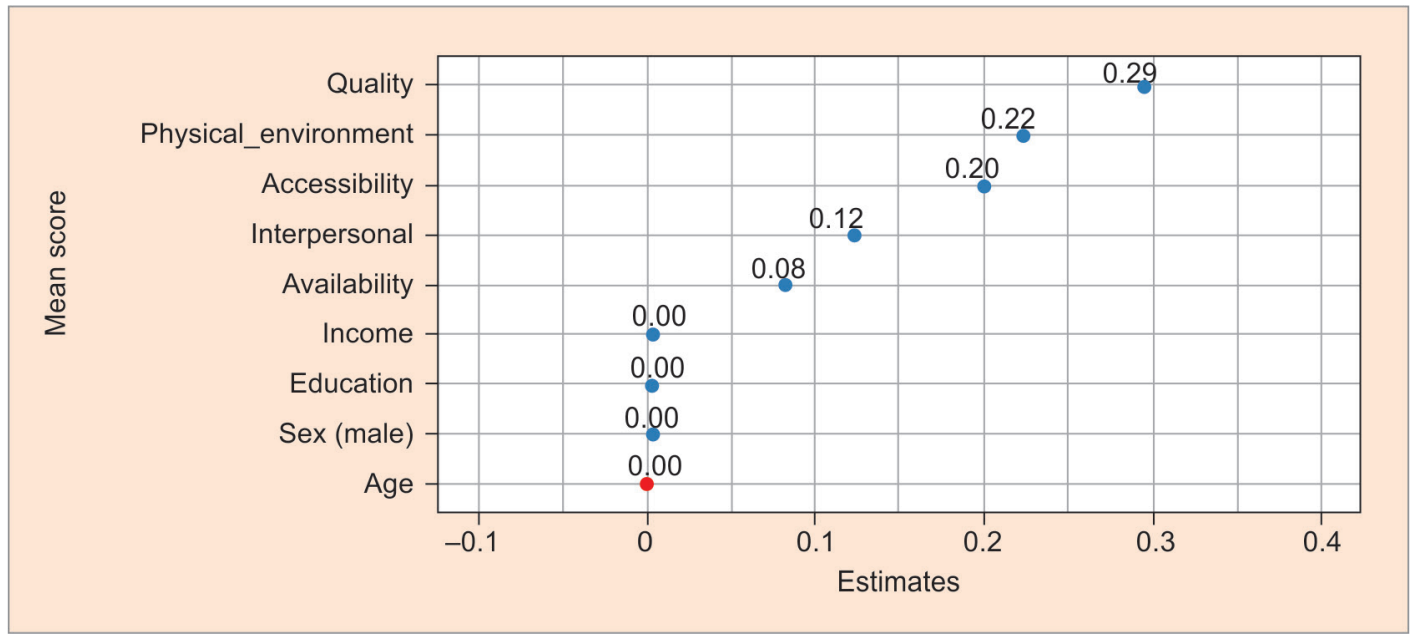

Annexure 7: Correlogram showing correlation between various items in our questionnaire

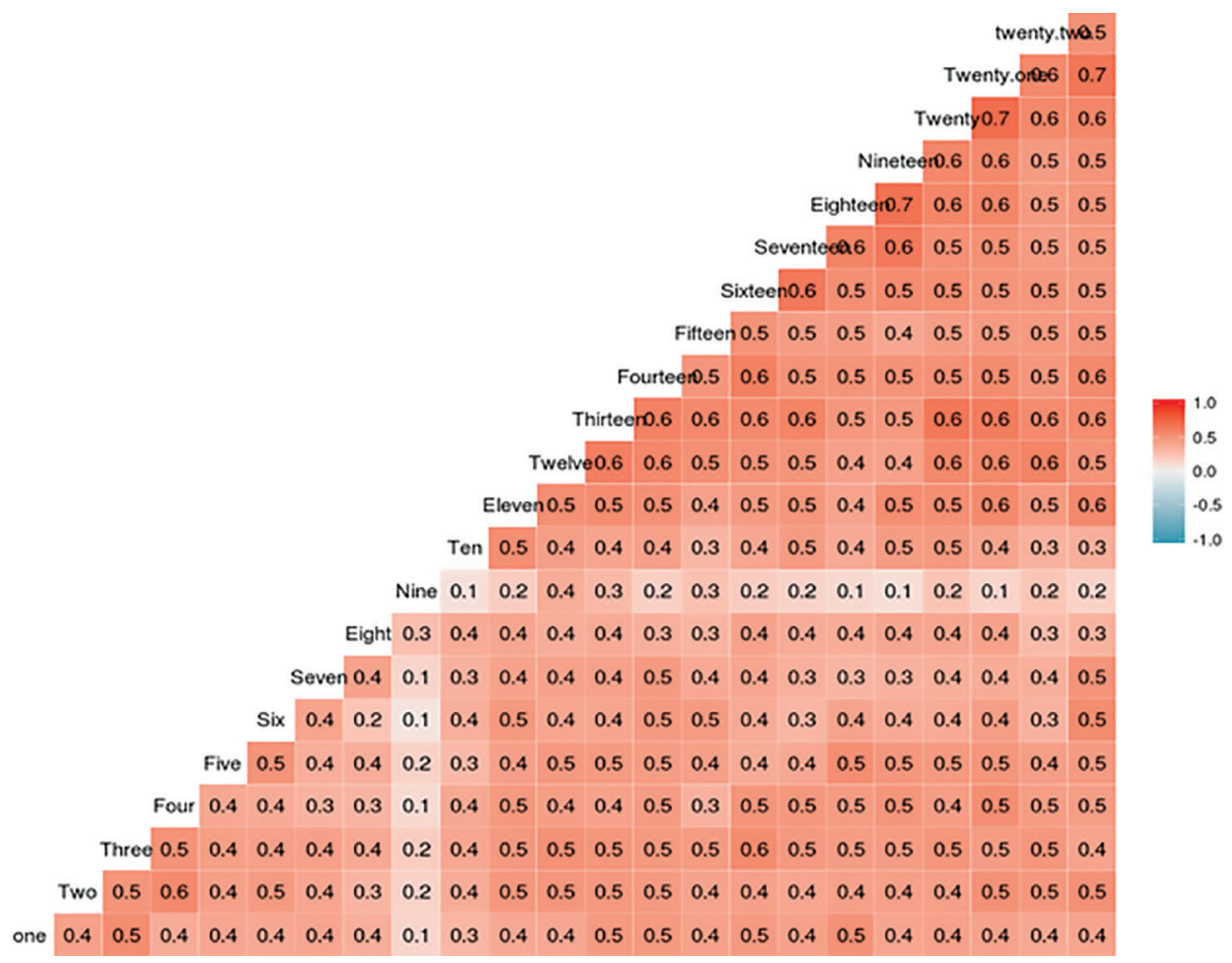

with average score given about 4 out of 5 , followed by low level of satisfaction $(n=72)$ with score of 3 given out of 5 and high level of satisfaction $(n=58)$ in which most of them marked maximum 5 out of 5 . The findings can be correlated with the distribution of scores in various groups shown in the figure.

\section{DISCUSSION}

The proportion of medium satisfaction was higher and the proportion of lower satisfaction was lower than other similar study by Net et al. ${ }^{19}$ However, in gross, it could be observed that in this unique kind of a pilot outreach
OPD by an apex government health center in India, the distribution of scores suggests that we need to keep up our performance in quality and interpersonal domain, while we need to improve in accessibility domain. Gross satisfaction level was quite positive, with a combined medium and high level of satisfaction constituting 330 out of $402(82.08 \%)$. At the same time, generally felt and quoted issues by most of the staffs working at the center that none of the patient availing this facility would be unsatisfied was disproved by the fact that 72 out of 402 (17.91) were low satisfied. Distribution of scores suggests that we need to keep up our performance in quality and 
interpersonal domain, while we need to improve in accessibility domain. Gender wise, the center catered a proportionally more female (54.65\%) against the sex ratio of 862 (46.29\%) of the Jhajjar district according to 2011 census. That is a remarkable note in a country like India, where women empowerment is being focused upon. The mean age of the population attending the clinic was 38 years (with standard deviation of 16 years), so mostly it was distributed around young population and the representation of the geriatric age group was lacking. The higher age group around mean of 40 years and lower age group of mean 35 years (in comparison with mean of total, i.e., 38 years) had low and high level of satisfaction respectively. While $83.1 \%$ of the population attending the facility were literate, given that the total literacy rate of the district is around $80 \%$ according to 2011 census. The majority of the subjects (52\%) of the population were educated up to secondary and senior secondary level. Irrespective of the education profile, almost in all such groups majority had medium level of satisfaction while illiterate and low education profile people had slightly higher proportion of low satisfaction level. Against the anticipation, the farmers constituted $13.4 \%$ of the total number of patients attending the health care facility at Jhajjar, while the total fraction of cultivators according to the 2011 census were $34.5 \%$. This may be explained by the geographical location of the Jhajjar health care facility. Other major observation was made that housewives and unemployed constituted around $48.3 \%$ of total patients under study. But almost in all occupation group, majority had medium satisfaction level. According to BG Prasad classification of socioeconomic status, most of the patients were belonging to upper to middle to upper class. High to lower middle class of people had medium to high level of satisfaction compared with lower socioeconomic class people where the majority of them had low level of satisfaction.

\section{CONCLUSION}

An outreach OPD attached to a full-fledged tertiary center having multispecialty facility is very much welcomed by the people. This kind of setting gives the consumers a specialized, hassle-free, smooth, and quality health care. This also de-loads the work burden of the main apex/tertiary center side by side and provides a quick and timely referral for the patient in remote areas. The Jhajjar outreach OPD by AIIMS, New Delhi, is an excellent example of the same. As shown in the study, this model sets a good example for the existing outreach OPD in India. These kinds of new centers across our nation are the need of the hour where AIIMS outreach OPD sets the ways to improve and reach high level of satisfaction.

\section{ACKNOWLEDGMENT}

The authors acknowledge cooperation from Sister Archana Yadav, nursing in charge of OPD Care center of AIIMS, outreach OPD, Jhajjar, Badsa, Haryana.

\section{REFERENCES}

1. WHO. The World Health Report 2000: health systems: improving performance. Geneva: WHO; 2000. [cited 2012 Jan 13]. Available from: http://www.who.int/whr/2000/en/ whr00_en.pdf.

2. Prasad B, Gupta VM. A qualitative assessment of ante-natal care provided by auxiliary nurse midwives. Indian J Public Health 1999 Oct-Dec;43(4):140-143.

3. Kunders, GD. Hospitals: planning, design and management. New Delhi: Tata McGraw-Hill Publishing Company, Ltd.; 1998. pp. 328-342.

4. Shippee TP, Henning-Smith C, Gaugler JE, Held R, Kane RL. Family satisfaction with nursing home care: the role of facility characteristics and resident quality-of-life scores. Res Aging 2017 Mar;39(3):418-442

5. Rashmi, Vijaykumar B. Client satisfaction in rural India for primary health care- a tool for quality assessment. Al Ameen J Med Sci 2010;3(2):109-114.

6. Ware, JE.; Snyder, MK.; Wright, WR. Development and validation of scales to measure patient satisfaction with medical care services. Vol. 1. Springfield (VA): NTIS Publ; 1976. pp. 288-329.

7. Kumari R, ldris MZ, Bhushan V, Khanna A, Agarwal M, Singh SK. Study on patient satisfaction in the government allopathic health facilities of Lucknow district, India. Indian J Community Med 2009 Jan;34(1):35-42.

8. Prasanna KS, Bashith MA, Sucharitha S. Consumer satisfaction about hospital services: a study from the outpatient department of a private medical college hospital at Mangalore. Indian J Community Med 2009 Apr;34(2):156-159.

9. Mosadeghrad AM. Factors influencing healthcare service quality. Int J Health Policy Manag 2014 Jul;3(2):77-89.

10. Bhattacharya A, Menon P, Koushal V, Rao KL. Study on patient satisfaction in a territory referral hospital. J Acad Hosp Adm 2003;15(1):2003-01-2003-06.

11. Qureshi W, Naikoo GM, Baba AA, Jan F, Wani NA, Hassan G, Khan NA. Patient Satisfaction at tertiary care Hospitals in Kashmir: A Study from The Lala Ded Hospital Kashmir India. Internet J Health 2009;8(2):1-2.

12. Sharma R, Sharma M, Sharma RK. The patient satisfaction study in a multispecialty tertiary level hospital, PGIMER, Chandigarh, India. Leadersh Health Serv 2011 Feb;24(1):64-73.

13. Verma A, Sharma RK. Evaluation of the exit proformas in use at special wards of a public-sector tertiary care hospital. J Acad Hosp Adm 2000;12(1):2000-01-2000-06.

14. Assefa F, Mosse A, Hailemichael Y. Assessment of clients' satisfaction with health service deliveries at Jimma university specialized hospital. Ethiop J Health Sci 2011 Jul;21(2): 101-109.

15. Sodani PR, Kumar RK, Srivastava J, Sharma L. Measuring patient satisfaction: A case study to improve quality of care at public health facilities. Indian J Community Med 2010 Jan;35(1):52-56.

16. Muhondwa EP, Leshabari MT, Mwangu M, Mbembati N, Ezekiel MJ. Patient satisfaction at the Muhimbili National 
Hospital in Dares Salaam, Tanzania. East Afr J Public Health 2008 Aug;5(2):67-73.

17. Suryakantha, AH. Community medicine with recent advances. 2nd ed. India: Jaypee Publication; 2010. p. 591.

18. Census. Jhajjar district: census 2011 data. Haryana: Census; 2011. [cited 2012 Dec 27]. Available from: http://www. census2011.co.in/census/district/222-jhajjar.html.
19. Net Ny, SermsriS, Chompikul J. Patient satisfaction with health services at the out-patient department clinic of Wangmamyen community hospital, Sakeao Province, Thailand. J Public Health 2007 Jan;5(2):33-42.

20. Dudala SR, Reddy KA, Prabhu GR. Prasad's socio-economic status classification - an update for 2014. Int J Res Health Sci 2014 Jul;2(3):875-878 